\title{
PROGRAM ASSERTIVENES TRAINING DAN PROGRAM PSIKO EDUKASI KELUARGA SEBAGAI MODEL DALAM PREVENSI ADIKSI GAME ONLINE PADA REMAJA DI KOTA PADANG
}

\author{
Renidayati, Suhaimi \\ (Poltekkes Kemenkes Padang)
}

\begin{abstract}
Excessive use of online games in adolescents can lead to addiction. Online game addiction is associated with limited time of rest, insomnia, sleep deprivation, academic decline, decreased self-esteem, and decreased life satisfaction with everyday life. Through Assertive Training Program and Psycho-educational Program in Families are expected to improve the ability of self-esteem, assertiveness and knowledge of teenagers to prevent the Online Game Addiction. The study design "Quasi-experimental pre-post test without control group" with an intervention of assertive Training Program and Psycho-Educational Program in Family. The results showed a difference of average in self-esteem, assertive behavior and knowledge of Online Games in the intervention group were given assertiveness training program and Psycho-educational program before and after the intervention with $P$ value of 0.000 ( $p$ $<0.05$ ). Expected that exercise of assertive program and Psycho-Educational Program in Families can be used as a model in the prevention of online game addiction in adolescents, for nurses, counseling teachers in schools, and in communities
\end{abstract}

Keywords: Assertive Training Program-Program Psycho-Education in familyaddiction of Online game

\begin{abstract}
ABSTRAK
Penggunaan game online yang berlebihan pada remaja dapat menyebabkan adiksi. Adiksi game online diasosiasikan dengan keterbatasan waktu istirahat, insomnia, pengurangan waktu tidur, penurunan akademik penurunan harga diri, dan penurunan kepuasan hidup dengan kehidupan sehari-hari. Melalui Program Latihan Asertif dan Program Psiko edukasi Keluarga diharapkan dapat meningkatkan kemampuan harga diri, asertivitas dan pengetahuan remaja untuk mencegah Adiksi Game Online. Desain penelitian "Quasi experimental pre-post test without kontrol group" dengan intervensi Program Latihan Asertif dan Program Psiko Edukasi Keluarga. Hasil penelitian menunjukan perbedaan rerata harga diri, perilaku asertif dan pengetahuan mengenai Game Online pada kelompok intervensi yang diberikan program latihan asertif dan Program Psiko edukasi Keluarga sebelum dan sesudah intervensi dengan $P$ value $0,000(p<0,05)$. Diharapkan Program Latihan asertif dan Program Psiko Edukasi Keluarga dapat digunakan sebagai model dalam prevensi Adiksi Game online pada remaja, bagi perawat, guru konseling di sekolah, maupun di komunitas
\end{abstract}

Kata kunci : Program Latihan asertif - Program Psiko Edukasi Keluarga- adiksi Game Online

\section{PENDAHULUAN}

Penggunaan game online yang berlebihan yang dapat berpengaruh negatif bagi pemain game tersebut. yang akhirnya menyebabkan terjadinya ketergantungan, berperilaku kompulsif dan tak acuh pada kegiatan lain yang disebut dengan adiksi. (Ruffin, N 2009). Berdasarkan survei Asosiasi Penyedia Jasa Internet Indonesia (APJII) tahun 2013 dalam Piyeke, P.J., Bidjuni, H., \& Wowiling, F. (2014), pengguna internet di Indonesia 
mencapai 71,19 juta dan tahun 2014 naik menjadi 145 juta.

Meskipun data tentang prevalensi penggunaan game online belum tersedia di Indonesia, namun data tersebut menyiratkan bahwa kemungkinan pengguna game online juga turut meningkat. Pencegahan (prevensi) remaja terlibat adiksi game online perlu adanya intervensi yang bersifat psikososial, maka perlu dirancang suatu program yang bertujuan untuk meningkatkan kompetensi pribadi dan sosial remaja tentang adiksi game online. Program ini disebut Program Latihan Asertif. Program Latihan Asertif ini dirancang untuk meningkatkan kompetensi personal dan sosial remaja.Penanganan secara dini adiksi game online pada remaja agar terhindar dari masalah serius tidak hanya berasal dari remaja sendiri namun dibutuhkan juga dari keluarga. Banyak keluarga yang mengalami stres akibat kecanduan/ adiksi game online yang dialami anaknya dikarenakan tidak mengetahui masalah dan cara penanganan adiksi game online. Terapi keluarga yang bisa digunakan dalam mengatasi adiksi game online adalah Program Psikoedukasi Keluarga (Stuart 2013).

Pemberian Program latihan Asertif dan program psikoedukasi keluarga untuk remaja dengan adiksi game online belum banyak dilakukan. Belum pernah dilakukannya Program latihan Asertif dan Program Psikoedukasi keluarga pada remaja di kota Padang dalam pencegahan Adiksi game online, menjadi latar belakang perlunya dilakukan Program latihan Asertif dan Program Psikoedukasi keluarga pada remaja di kota Padang khususnya di SMAN 5 Padang.

\section{METODE PENELITIAN}

Penelitian menggunakan desain Quasi eksperimen pendekatan pretest posttest with kontrol group. Penelitian dilaksanakan di SMAN 5 Padang dari bulan Maret sampai dengan Nofember 2016. Sampel penelitian adalah 62 Siswa SMAN 5 Kota Padang Tahun Ajaran 2015/2016.Teknik pengambilan sampel purposive sampling (Lemeshow 1997). Data diolah dan dianalisa dengan analisa univariat yaitu dengan statistik deskriptif dan Analisa bivariat menggunakan uji uji independent, Sample T-Test dan uji Anova

\section{HASIL PENELITIAN}

Tabel 1. Karakteristik Responden Menurut Jenis Kelamin di SMA 5 Kota Padang Tahun $2016(n=64)$

\begin{tabular}{|c|c|c|c|c|}
\hline Karakteristik & $\begin{array}{l}\text { Kelompok } \\
\text { FPE dan TS }\end{array}$ & $\begin{array}{c}\text { Kelompok } \\
\text { TS }\end{array}$ & Total & P. Value \\
\hline & $\%$ & $\%$ & $n$ & \\
\hline
\end{tabular}

1. Jenis Kelamin

\begin{tabular}{|c|c|c|c|c|c|c|c|c|}
\hline a. & Laki- Laki & 20 & 62,5 & 18 & 56,25 & 38 & 59,38 & 0,074 \\
\hline b. & Perempuan & 12 & 37,5 & 14 & 43,75 & 26 & 40,62 & \\
\hline
\end{tabular}


Berdasarkan tabel 1 menunjukkan lebih separoh (62,5\%) responden laki-laki pada kelompok yang mendapat Program Latihan Asertif dan Program Psiko edukasi keluarga dan lebih separoh $(59,38 \%)$ responden laki-laki pada Kelompok yang diberikan Program latihan Asertif saja .

Uji kesetaraan antara kelompok yang mendapatkan Program Latihan Asertif dan Program Psiko edukasi keluarga dan kelompok yang hanja mendapatkan Program Latihan Asertif adalah setara ( $p$ value $>0,05$ ).

Tabel .2 Karakteristik Responden Menurut Usia di SMA 5 Kota Padang Tahun 2016 ( $n=64$ )

\begin{tabular}{lllllllll}
\hline Karakteristik & $\begin{array}{l}\text { Jenis } \\
\text { Kelompok }\end{array}$ & $\mathrm{n}$ & Mean & SD & $\begin{array}{l}\text { Min } \\
\text { Maks }\end{array}$ & $\begin{array}{l}\text { 95\% } \\
\mathrm{Cl}\end{array}$ & $\mathrm{F}$ & $\mathrm{Pv}$ \\
\hline \multirow{3}{*}{ Usia } & TS \&FPE & 32 & 16,51 & 1,067 & $15-19$ & $16,15-16,88$ & 32 & 0,2 \\
\cline { 2 - 9 } & TS & 32 & 16,70 & 1,024 & $15-18$ & $16,36-17,04$ & 32 & 0,2
\end{tabular}

Berdasarkan Tabel 2 diketahui rata-rata usia responden yang mendapatkan latihan Asertif dan Program psiko edukasi keluarga adalah 16,51 tahun dengan standar deviasi 1,067 dengan usia termuda 15 tahun dan tertua 19 tahun. Dan Responden yang hanja mendapatkan Program latihan asertif Rata- rata usianya 16,70 tahun dengan dengan standar deviasi1,024 dengan usia termuda 15 tahun dan usia tertua 18 Tahun.

Tabel 3. Analisis Scor Harga diri, kemampuan asertif dan pengetahuan adiksi game online Responden di SMA Kota Padang Tahun 2016 ( $n=64)$

\begin{tabular}{lllrrrrr}
\hline Kemampuan & $\begin{array}{l}\text { Jenis } \\
\text { Kelompok }\end{array}$ & Mean & SD & $\begin{array}{l}\text { Min } \\
\text { Maks }\end{array}$ & $\begin{array}{l}95 \% \\
\text { Cl }\end{array}$ & F & Pv \\
\hline \multirow{2}{*}{ Harga diri } & TS \&FPE & 12,65 & 1,678 & $10-20$ & $12,18-12,46$ & 32 & 0,2 \\
\cline { 2 - 9 } & TS & 13,20 & 1,907 & $10-21$ & $12,18-13,28$ & 32 & 0,2 \\
\hline $\begin{array}{l}\text { Perilaku } \\
\text { Asertif }\end{array}$ & TS \& FPE & 10,28 & 6,7 & $2-27$ & $7,86-12,7$ & 32 & 0,2 \\
\cline { 2 - 9 } & TS & 14,22 & 7,2 & $1-30$ & $11,6-$ & 32 & 0,2 \\
\hline $\begin{array}{l}\text { Pengetahuan } \\
\text { Adiksi Game } \\
\text { oline }\end{array}$ & TS \& FPE & 10,28 & 6,7 & $2-27$ & $7,86-12,7$ & 32 & 0,2 \\
\cline { 2 - 9 } & TS & 14,22 & 7,2 & $1-30$ & $11,6-$ & 32 & 0,2 \\
\hline
\end{tabular}


Tabel 4. Perubahan Adiksi Game Online Remaja Sebelum dan Sesudah Program Latihan asertif dan Program Psiko edukasi Keluarga di SMAN 5 Padang Tahun 2016

\begin{tabular}{ccccccc}
\hline Kelompok & Adiksi & $\mathrm{N}$ & Mean & SD & SE & \multirow{2}{*}{ P Value } \\
& Sebelum & 32 & 33,91 & 4,321 & 0,764 & \\
\multirow{2}{*}{ AT dan FPE } & Sesudah & 32 & 27,31 & 2,799 & 0,495 & \\
\cline { 2 - 5 } & Selisih & \multicolumn{5}{c}{6,000} \\
\cline { 2 - 5 } AT & Sebelum & 32 & 32,44 & 2,873 & 0,508 & \multirow{2}{*}{0,000} \\
& Sesudah & 32 & 28,28 & 1,611 & 0,285 & \\
\cline { 2 - 4 } & Selisih & \multicolumn{3}{c}{4,16} & & \\
\hline
\end{tabular}

Berdasarkan tabel 4 diketahui bahwa rata-rata kondisi adiksi Game Online pada kelompok yang diberikan Program Latihan Asertif dan Program psikoedukasi keluarga sebelum intervensi 33,91 dimana berada pada kondisi tingkat berat dengan standar deviasi 4,321 setelah diberikan intervensi rata-rata kondisi Adiksi Game Online menjadi 27,31 dimana berada pada kondisi tingkat sedang dengan standar deviasi 2,799. Hasil uji statistik menunjukkan ada penurunan bermakna rata-rata kondisi sebelum dan sesudah diberi intervensi Program Latihan Asertif dan psikoedukasi keluarga dengan nilai $p=0,000$ ( $P$ Value $<0,05$ )

Rata-rata kelompok yang hanya mendapatkan Program Latihan Asertif sebelum diberikan intervensi 32,44 dengan standar deviasi 2,873 setelah diberikan intervensi rata rata kondisi menjadi 28,28 dengan standar deviasi 1,611 Hasil uji statistik menunjukkan ada penurunan bermakna rata- rata kondisi sebelum dan sesudah intervensi Program Latihan Asertif dengan nilai $p=0,000$ ( $P$ Value $<0,05$ ). Pada kelompok yang diberikan Program Latihan Asertif dan psikoedukasi keluarga penurunan kondisi adiksi sebesar 6,6 Pada kelompok yang hanya mendapat Program Latihan Asertif kondisi adiski sebesar 4,16

\section{PEMBAHASAN}

Bermain game online bagi remaja merupakan hal yang mengasikkan dan merupakan pengalaman yang luar biasa jika dapat berhubungan dengan orang lain via internet. Hal-hal yang berdampak buruk bagi pemain game online dirasakan oleh orang-orang sekitarnya karena pemain game online hanya merasakan kesenangan bermain saja tanpa batasan ruang dan waktu. Hasil penelitian menunjukan bahwa remaja yang mendapatkan Program Latihan Asertif dan Program Psikoedukasi keluarga kondisi adiksinya sesudah intervensi menurun lebih besar secara bermakna dibanding remaja yang hanya mendapat Program Latihan Asertif ( $\mathrm{P} V<0,05)$. Terdapat perbedaan bermakna antara kelompok yang mendapatkan terapi penghentian pikiran dan psikoedukasi keluarga dengan kelompok yang hanya mendapatkan terapi penghentian pikiran ( $p$ value $<0,05$ )

Hasil analisis menunjukkan harga diri remaja yang mengikuti Program Latihan asertif dan Program Psikoedukasi Keluarga meningkat secara bermakna ( $P$ value $<0,05)$. 
Harga diri remaja yang tidak mengikuti program Assertive Training juga meningkat secara bermakna ( $P$ value $<0,05)$. Harga diri remaja yang mengikuti program Assertive Training terlihat lebih tinggi dibandingkan dengan remaja yang hanja mendapatkan Program Latihan asertif.

Sanditaria (2012) menyatakan bahwa remaja yang telah menjadi mengalami Adiksi Game Online berdampak kepada prestasi belajar yang buruk, kegiatan sekolah berkurang dan merasa dikucilkan dan terasing dari teman-temannya. Hasil penelitian Yang (2005) dalam Santaria (2012), pada siswa yang mengalami adiksi internet di Korea menunjukkan bahwa siswa dengan adiksi internet dengan mudah dipengaruhi oleh perasaan, emosional, kurang stabil, imajinatif, tenggelam dalam pikiran, mandiri, bereksperimen, dan lebih memilih keputusan sendiri.

Menurut Nike ( 2015), Adiksi Game Online pada remaja terjadi karena beberapa penyebab yakni gaya hidup keluarga, predisposisi alkohol, tekanan kelompok sebaya, kekacauan keluarga dan masalah psikologis dan religius. Hawari (2006), menambahkan faktor kepribadian mempunyai peranan penting disamping faktor fisiologik. Faktor kepribadian yang berperanan dalam penyalahgunaan Adiksi Game Online meliputi aspek intrapersonal, aspek interpersonal dan aspek kognitif.

Aspek intrapersonal yang diidentifikasi berperan penting dalam penyalahgunaan Adiksi Game Online adalah rendahnya harga diri remaja. Remaja dengan harga diri yang rendah merasa dirinya terasing tertekan dan kurang memiliki keberanian untuk berbuat sesuatu. Mereka cendrung lebih cemas, mudah depresi, pesimis akan masa depannya dan mudah gagal. Selanjutnya remaja tersebut mudah mendapatkan pengaruh dari lingkungan untuk mengkonsumsi Adiksi Game Online.

Penelitian Syahran (2011) memaparkan bahwa ketika remaja terlibat Adiksi Game Online, mereka merasakan dirinya tidak berguna, putus asa, hampa, berbagai perasaan negatif karena tidak ada teman dan tidak ada orang yang memperdulikannya.,dapat ditingkatkan kemampuannya dengan memberikan suatu program latihan yang bertujuan untuk meningkatkan kompetensi personal dan interpesonal berdasakan pendekatan kognitif behavioral.

Hasil penelitian yang telah dilakukan dan didukung hasil penelitian terdahulu membuktikan Program latihan asertif dan Program Psiko edukasi keluarga berpengaruh dalam meningkatkan perilaku asertif dan meningkatkan harga diri remaja. Menurunnya kondisi adiksi remaja, didukung pelaksanaan latihan dikomunikasikan secara terbuka dengan remaja, kontrak yang jelas dan pemberian reinforment positif senantiasa diberikan kepada remaja.

Kontrol dan pengawasan orang tua sangat berperan dalam aktifitas remaja. Penurunan kondisi adiksi remaja disebabkan karena dukungan keluarga. Menurut Friedman (2010) dukungan emosional keluarga merupakan fungsi afektif yang harus diterapkan pada Penerbit: Poltekkes Kemenkes Padang, http://jurnal.poltekKespadang.ac.id/ojs/index.php/jsm 
keseluruhan anggota keluarga. Penelitian yang dilakukan oleh Rahayu, Hamid, Sabri (2011) menunjukkan bahwa dukungan psikologis keluarga pada kelompok intervensi sebelum psikoedukasi keluarga sebesar 45,57 meningkat menjadi 52,53. Dengan pemberian psikoedukasi keluarga mampu meningkatkan kemampuan remaja dalam memberikan dukungan psikologis dan sosial kepada remaja yang mengalami ketergantungan game online

Menurut Ruffin, N (2009) aspek interpesrsonal atau kemampuan melakukan hubungan sosial dengan orang lain yang diidentifikasi berperan penting dalam Adiksi Game Online pada remaja adalah rendahnya perilaku asertif remaja. Remaja dengan kemampuan asertif yang rendah tidak mampu menghadapi tekanan kelompok, termasuk menolak bujukan bermain Game Online.

Stuart,G.W \& Laraia, M.T (2005) menyatakan melalui program Latihan Asertif pada remaja dapat menyampaikan perbedaan pendapat dengan orang lain. Perbedaan pendapat bukan sesuatu yang harus dihindari tapi sesuatu yang nature, harus disampaikan dengan cara yang baik dan santun sehingga orang lain merasa tidak tersinggung atau terjadi kesalahpahaman (Aini, 2010).

Program Latihan Asertif yang bertujuan meningkatkan adaptasi dalam berbagai situasi sehingga mengurangi terjadinya kolaps, pasif, dan rasa bermusuhan yang meledak mencakup. Membantu mendapatkan citra positif diri sendiri. Mengembangkan perasaan saling menghargai dengan orang lain. Mencapai tujuan tanpa konflik dengan orang lain. Melindungi diri agar tidak dimanfaatkan orang lain. Melindungi diri agar tidak melukai perasaan orang lain. Tidak mudah terpancing emosi Membangun hubungan interpersonal dengan orang lain. Melalui pengembangan program Assertive Training yang dilatihkan kepada remaja diharapkan Adiksi Game Online pada remaja bisa ditekan.

Penelitian ini dikuatkan oleh Stuart,G.W \& Laraia, M.T (2005), dengan program Latihan Asertif yang diberikan pada remaja dapat melatih remaja cara menyampaikan harapan terhadap perubahan yang lebih baik sehingga dapat meminimalkan kesalah paahaman yang terjadi. Penilaian (assesment) Adiksi Game Online diperlukan dalam upaya intervensi dalam usaha prevensi. Dalam upaya prevensi pada penilaian Adiksi Game Online pada remaja lebih ditekankan pada deteksi untuk menimbulkan perhatian, rasa ingin tahu dan kepedulian untuk menghindari terlibat dalam Adiksi Game Online dengan memberikan penyuluhan tentang Adiksi Game Online.

Penanganan secara dini ini agar terhindar dari masalah serius tidak hanya berasal dari remaja sendiri namun dibutuhkan juga dari keluarga. Banyak keluarga yang mengalami stres akibat remaja kecanduan game online dikarenakan tidak mengetahui masalah dan cara penanganan anggota keluarga yang mengalami adiksi game online yang tepat.

Terapi keluarga yang bisa digunakan dalam mengatasi adiksi game online pada remaja adalah family psychoeducation theraphy (terapi psikoedukasi keluarga, Stuart Penerbit: Poltekkes Kemenkes Padang, http://jurnal.poltekKespadang.ac.id/ojs/index.php/jsm 
2013). Terapi ini berupa pemberian informasi dan edukasi melalui komunikasi terapiutik yang melibatkan keluarga. Program Psikoedukasi merupakan pendekatan yang bersifat edukasi dan pragmatik ( Stuart, 2013). Family Psychoeducation Theraphy adalah terapi yang tepat untuk diberikan pada keluarga dengan anggota keluarga yang mengalami gangguan kesehatan baik penyakit fisik maupun gangguan jiwa. Tujuan dari terapi keluarga ini diharapkan keluarga memahami masalah yang dialami oleh anggota keluarga, serta mampu mengatasi masalah pada diri sendiri yang muncul karena adanya anggota keluarga yang mengalami adiksi.

Keluarga merupakan elemen penting dalam memberikan dukungan sosial pada remaja. Hal ini terjadi dikarenakan keluarga mampu memberikan ketenangan, berdasarkan agama dan keyakinan yang dianut oleh sesama anggota keluarga. Sehingga keluarga merupakan pendukung sosial yang sangat baik.

Menurut Stuart ( 2013) psikoedukasi keluarga merupakan salah satu cara yang dapat dilakukan oleh perawat diarea komunitas dalam melakukan penyelesaian masalahmasalah psikologis yang terkait dengan masalah fisik dan psikologis yang terjadi pada anggota keluarga, dengan melakukan psikoedukasi maka seorang perawat akan dapat langsung memberikan pelayanan yang efektif dan efisien untuk menyelesaikan masalah disetiap keluarga. Psikoedukasi keluarga dapat meningkatkan kesejahteraan keluarga serta menurunkan beban subjektif keluarga.

Hasil penelitian yang telah dilakukan dan didukung hasil penelitian terdahulu membuktikan Program Latihan Asertif berpengaruh dalam meningkatkan perilaku asertif remaja dibandingkan dengan remaja yang tidak mengikuti program Latihan Asertif .Peningkatan kemampuan perilaku asertif remaja setelah mengikuti program Latihan Asertif, didukung pelaksanaan latihan dikomunikasikan secara terbuka dengan remaja , kontrak yang jelas dan pemberian reinforment positif senantiasa diberikan kepada remaja.

Hasil penelitian yang dilakukan didapatkan ada perbedaan tanda-tanda Adiksi Game Online pada kelompok intervensi yang dilakukan program Latihan Asertif dan Latihan Psiko edukasi Keluarga dengan kelompok yang hanja diberikan Program Latihan Asertif tentang Adiksi Game Online dua bulan intervensi diberikan pada remaja. Hasil penelitian yang dilakukan peneliti berpendapat bahwa aspek personal berupa peningkatan harga diri remaja, latihan perilaku asertif dan peningkatan pengetahuan mengenai Adiksi Game Online yang diberikan kepada remaja secara terprogram merupakan upaya untuk mencegah terjadinya Adiksi Game Online pada remaja.

\section{KESIMPULAN DAN SARAN}

Hasil penelitian menunjukkan ada penurunan bermakna kondis adiksi game online sebelum dan sesudah diberi intervensi Program Latihan Asertif dan psikoedukasi keluarga.Pada kelompok yang diberikan Program Latihan Asertif dan psikoedukasi keluarga Penerbit: Poltekkes Kemenkes Padang, http://jurnal.poltekKespadang.ac.id/ojs/index.php/jsm 
penurunan kondisi adiksi sebesar 6,6 dan pada kelompok yang hanya mendapat Program Latihan Asertif penurunan kondisi adiksi sebesar 4,16.

Diharapkan Program Latihan asertif dan Program Psiko Edukasi Keluarga dapat digunakan sebagai model dalam prevensi Adiksi Game online pada remaja, bagi perawat, guru konseling di sekolah, maupun di komunitas.

\section{DAFTAR PUSTAKA}

Baer, S., Bogusz, E., \& Green, D. A. (2011). Stuck on Screens: Patterns of Computer Canadian Academy Of Child \& Adolescent Psychiatry, 20(2), 86-95.

Brunborg, G. S., Mentzoni, R. A., \&Frøyland, L. R. (2014). Is Video Gaming, or Video Game Addiction, Associated with Depression, Academic Achievement, Heavy Episodic Drinking, or Conduct Problems? Journal of Behavioral Addictions, 3(1), 2732. doi:10.1556/JBA.3.2014.002

Fortinash, K.M. \& Worret, P.A.H. (2012). Psychiatric Mental Health Nursing Fifth Edition. St.Louis: Elsevier.

Griffiths, M.D. (2010). The Role of Context in Online Gaming Excess and Addiction: Some Case Study Evidence. Int J Ment Health Addiction, 9, 119-125. doi: 10.1007/s11469009-9229-x

Hollen, K.H. (2009). Encyclopedia of Addiction. USA: Greenwood Publishing Group Inc.

King, D. L., \& Delfabbro, P. H. (2014). Internet Gaming Disorder Treatment: A Review of Definitions of Diagnosis and Treatment Outcome. Journal Of Clinical Psychology, 70(10), 942-955. doi:10.1002/jclp.22097

Kuss, D. J. (2013). Internet gaming addiction: current perspectives. Psychology Research \& Behavior Management, 6125-137. doi:10.2147/PRBM.S39476

Lee, J. Y., Shin, K. M., Cho, S.-M., \& Shin, Y. M. (2014). Psychosocial Risk Factors Associated with Internet Addiction in Korea. Psychiatry Investigation, 11(4), 380- 386. doi:10.4306/pi.2014.11.4.380

Nike, Puspita. (2015). Fenomenologi Psikososial Pada Remaja Dengan Adiksi Game Online Di Kelurahan Surau Gadang Kecamatan Kota Padang ( Tesis) Tidak di Publikasikan

Piyeke, P.J., Bidjuni, H., \& Wowiling, F. (2014). Hubungan Tingkat Stres dengan Durasi Waktu Bermain Game Online pada Remaja di Manado. E-Journal Universitas Sam Ratulangi, 2(2), 1-7.

Ruffin, N. (2009). Adolescent Growth and Development, Virginia Cooperative Extension, Family and Child Development Publication. 350-850

Sanditaria, W., Fitri, S.Y.R., \& Mardhiyah, A. (2012). Adiksi Bermain Game Online pada Anak Usia Sekolah di Warung Penyedia Game Online Jatinangor Sumedang. eJurnal Unpad, 1(1). Fakultas Ilmu Keperawatan Universitas Padjajaran. Diakses dari http://jurnal.unpad.ac.id/ejournal/article/view/745/791 pada tanggal 15 Maret 2015.

Stuart, G.W. (2013). Principles and Practice of Psychiatric Nursing. China: Elsevier Inc. 